Article

\title{
Conversion of Dual-Use Technology: A Differential Game Analysis under the Civil-Military Integration
}

\author{
Xia Cao ${ }^{1}$, Xiaojun Yang ${ }^{1, *}$ and Lupeng Zhang ${ }^{2}$ \\ 1 School of Economics and Management, Harbin Engineering University, Harbin 150001, China; \\ caoxia@hrbeu.edu.cn \\ 2 School of Public Administration, Beijing University of Aeronautics and Astronautics, Beijing 100191, China; \\ zhanglupeng@buaa.edu.cn \\ * Correspondence: jamers@hrbeu.edu.cn; Tel.: +86-1520-4610-379
}

Received: 5 October 2020; Accepted: 10 November 2020; Published: 12 November 2020

check for updates

\begin{abstract}
Civil-military integration enables the symmetry development of dual-use technologies in the defense and civilian areas. In this paper, we used stochastic differential game theory to build theoretical models of the dual-use technology conversion between a military firm and a civilian firm. The models include three directions of dual-use technology conversion, namely, spin-off, spin-in, and mix. In particular, we incorporate the dynamic development of dual-use technology into the research framework. Our results show that the order of the Pareto optimality results is mix, spin-in, spin-out, including the best effort, the highest revenue, and the most technology value-added. The results also indicate that: (1) Some random interference factors can affect the transfer efforts, such as the coefficient of technological innovation capability and cost coefficients. (2) The military subsidies factor is an inventive mechanism that can promote dual-use transfer from the civilian firm to the military. (3) The military enterprise only earns more than the civilian firm in spin-in. (4) The growth of models in the dual-use technology conversion process faces increased technology uncertainty.
\end{abstract}

Keywords: dual-use technology conversion; civilmilitary integration (CMI) model; differential game

\section{Introduction}

As a sustainable development policy, civil-military integration was listed in China's national strategy by the Chinese government in 2015. Subsequently, the conversion of dual-use technology has received widespread attention from policy-makers and enterprise managers. In 2017, the Chinese government included the conversion of dual-use technology in its national development planning. Dual-use technology refers to technology developed and used for both economic and defense aims [1]. The conversion of dual-use technology means that the technology is generated in the military (or civilian) enterprise and is applied in the civilian (or military) market, or is directly used in dual-use production.

Defense expenditure, economic development, and technological innovation have been the focuses of scholarly attention [2]. In addition to the technological and economic environment, changes in international competition have driven the transformation of military and civilian enterprises. Military firms are state-owned enterprises (SOEs) under the control of CSTIND (the Commission for Science, Technology, and Industry for National Defence). Due to the self-sufficient system and the military's role as a monopsonistic buyer, redundancy in personnel and low efficiency of productivity could be a barrier to military enterprises [3]. In contrast, civilian companies need to survive in a fast-changing, competitive market but are nonetheless attracted by high and stable military demand. These issues encourage the transformation of military and civilian enterprises. Dual-use technology conversion can activate the interactions of the defense innovation and economic systems, thereby solving 
the problem of promoting a high-tech military technology under limited budgets, and improving economic value [4]. Dual-use technology conversion is becoming inevitable in civil-military integration (CMI) in China [5].

Dual-use technology conversion is a process of technology transfer and development [6]. It is implemented through the introduction of external technologies, expansion to another market, and continuous innovative activities to develop dual-use technologies [7]. Military and civilian enterprises can be both the suppliers and the recipients of the technology under different conditions. Thus, three models of convergence are provided in the technology sources [8], namely, "spin-off," "spin-in," and "mix" [9]. Scholars have studied the characteristics of these three models and the issues to be addressed.

First, dual-use in which defense technology is used in commercial applications is referred to as spin-off [10]. Due to the state ownership of the military enterprise, a military firm needs to adjust its characteristics to an entirely competitive market environment. Institutional reform, security, and technology need to be taken into account when transferring dual-use technology. Jing [5] studied how the military firm converted into the civilian market from the institutional regime's perspective. Mowery [11] argued that the natural precision and exclusiveness of military technology requires supporting facilities at a level that far exceeds the typical facilities present in a civilian production system. FitzGerald and Parziale [12] pointed out that, although the presence of military products is expanding in the private market, defense technologies are declining.

Second, the use of civilian production facilities to produce arms or military products is referred to as spin-in [13]. Regarding the means by which the civilian use of knowledge is embedded in the military area, numerous scholars have examined patent citations, competitive pricing, military agency, etc. $[10,14]$. These studies found that higher technical standards and specifications act as a technology transfer barrier for the civilian industry [15]. A military firm purchases from the civilian sector when technology and products meet or exceed defense standards [16]. A civilian enterprise is eligible to provide ancillary production services for the defense system only if it has passed the audit and received "Three Military Certificates" [8]. Furthermore, it is difficult for the civilian enterprise to gather defense demand information because private companies are outsiders to the defense system [17].

Finally, the production of technology used in both economic and defense areas is referred to as mix. Although technology can be used for both sides [18], the final product needs to be implemented across different product lines and serve different areas [19]. The military production process needs advanced research, and production begins after the completion of the design [20]. In contrast, commercial manufacturers tend to compress the time of the product development cycle to decrease costs and improve market competitiveness [21]. If one firm specializes in military and civilian operational modes simultaneously, high efficiency and high cost will co-exist [22]. Thus, it is argued that dual-use technologies are more likely in the early stage of development, which has more generous room for an experimental variety [1], and the differences in objectives often tend to reduce the potential of dual-use technologies.

Scholars have studied the dual-use technology conversion from the perspective of the three conversion models, spin-off, spin-in, and mix. Based on these three models, the symmetry relationship between military and civil enterprises is shown in Figure 1. However, most research adopts one or two transfer modes in one framework. Furthermore, both military firms and civilian firms, regardless of the model adopted, can pay an additional bill for the transfer cost, which can be considered in both sides' willingness and behavior.

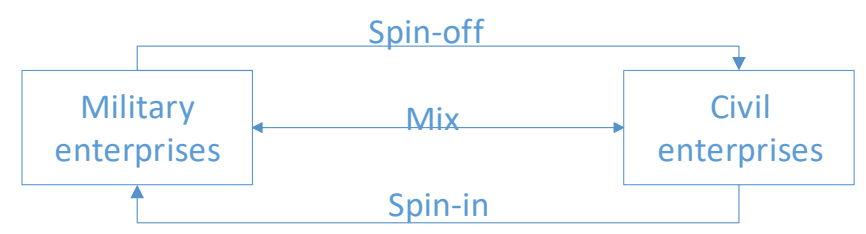

Figure 1. Three models of dual-use technology conversion. 
In addition, the conversion of dual-use technologies is also reflected in technology development. The process of technology transfer leads to changes in the dynamics of technology development. Teece (1976) pointed out that technological transfers between many companies are entirely different from the R\&D process itself. When the receiver absorbs external technology, there is "learning by doing" in the transmission process. The receiver makes adjustments according to their own needs and expands the feasibility of the technology to meet its standards. Thus, technology undergoes continuous development and change. This dynamic evolution will interact with the behavior of decision-makers in uncertain conditions [23], and should be allowed for in the study of dual-use technology conversion to address active competition and cooperation over a continuous period [24].

Therefore, we aimed to analyze the dual-use technology conversion between military and civilian firms, including the three models of dual-use technology transfer and dynamic development during the CMI process. The military firms studied belong to the top ten military-industrial groups, and the related civilian enterprises are mostly large organizations. Thus, several models of CMI exist simultaneously. This paper fills the gap in the analysis regarding the comparison of dual-use technology transfer modes and considers the development of technology, realization of the transfer, and development within the same research framework.

Recently, game theory has emerged as a mainstream model to study technology conversion. As examples, Wang and Blomström studied multinational technology transfer [25], and Koessler studied technology transfer using the Bayesian and three-stage game models [26]. Podvezko applied this theory to the process of building technology and management [27]. Game theory leads to accurate decisions and can clearly describe the actors' characteristics and explain the relationship between them [28]. However, standard game theory cannot resolve the problem of dynamic development. Thus, we chose to use the stochastic differential game theory to describe dual-use technology conversion between military and civilian firms in the CMI. Stochastic differential game theory can address the military and civilian firms' characteristics, identify the uncertainty of their relationships, and analyze the dynamic development of dual-use technology in one mode.

Therefore, according to the three directions of dual-use technology conversion, we chose a military enterprise and a civilian enterprise as the two players and applied three types of stochastic differential game (Nash non-cooperative game, Stackelberg game, and cooperative game) to interpret spin-off, spin-in, and mix. This research aimed at building a reasonable and practical theoretical model to study the conversion of dual-use technology in the three CMI models.

The paper's structure is organized as follows: In the next section, we provide the dual-use technology conversion's stochastic differential game formulation for military and civilian firms. We resolve models of spin-off, spin-in, and mix with the Nash non-cooperative game, Stackelberg game, and cooperative game, respectively. Then, we compare and analyze the equilibrium results and present a simulation. Conclusions are drawn at the end of the paper.

\section{Model Design}

Military and civilian technological production occurs in two different market environments. Military technology has lengthy experimental and production cycles, with high technical demands and costs in an independent and autonomous market. In contrast, the civilian industry exists in an open and quickly changing macroeconomic environment, which needs lower prices, higher qualifications, and more product functions to attract consumers. Hence, when military and civilian firms enter each other's market, they could face complex competitive and cooperative relationships in the process of dual-use technology conversion.

\section{Stochastic Differential Game Models}

To simplify the dual-use technology conversion between defense and economics innovation systems in civil-military integration (CMI), we divide them into two economic groups: military firms 
(M) and civilian firms (C). We assume that the participating groups are entirely rational, possess full information, and aim to maximize their profits [29].

As the technology provider and receiver, military and civilian firms' intentions could be affected by technical confidentiality and the ownership interest in the access to dual-use technology [30]. Moreover, as a result of China's long-separated defense and civilian innovation systems, the distinction between military and civilian technology is institutional rather than intrinsic. These differences potentially lead the military and civil firms to a "lock-in" phase of the path-dependent process [31], restricting technology transfer options. Military and civil enterprises need to make additional efforts and payments for communication and external management. Let $E_{M}(t)$ denote the technology conversion effort level of military firms at time $t$, and $E_{C}(t)$ denote the effort level of civilian firms in the dual-use technology transfer. Given the convexity of cost, the functional expression of the cost of technology conversion for military and civilian firms can be denoted by $c_{M}\left(E_{M}(t), t\right)$ and $c_{C}\left(E_{C}(t), t\right)$, respectively, which uses quadratic functions to describe the relationship with cost and effort level at time t. Consider:

$$
c_{M}\left(E_{M}(t), t\right)=\frac{\mu_{M}}{2} E_{M}(t)^{2} c_{C}\left(E_{C}(t), t\right)=\frac{\mu_{C}}{2} E_{C}(t)^{2}
$$

where $\mu_{M}$ and $\mu_{C}$ respectively denote the cost coefficients of military and civilian firms at time $t$.

In the process of the CMI, the dual-use technologies will be transferred with cooperation and communication between military and civilian firms. External acquisition and internal transformation of dual-use technologies will continuously improve the development of the overall technical level [32]. Dual-use technologies upgrade as they are exported from one enterprise and received by another. The provider may regulate the technology at output according to the other side's situation. Throughout "learning by doing," the recipient accepts the new technology in a way that the researchers and facilities need. In a sense, technology development is charged by the conversion effort of military and civil firms. Let $K(t)$ denote the level of dual-use technologies, which is governed by the stochastic differential equation:

$$
\left\{\begin{array}{l}
d K(t)=\left[\alpha E_{M}(t)+\beta E_{C}(t)-\delta K(t)\right] d t+\varepsilon(K(t)) d z(t) \\
K(0)=K_{0} \geq 0
\end{array}\right.
$$

where $\delta \in(0,1]$ is the attenuation coefficient of dual-use technology; $\alpha$ and $\beta$ represent the coefficients of the technological innovation capability of military and civilian firms on the improvement of technical level; $z(t)$ and $\varepsilon K(t)$ are the standard Wiener process and random interference factors of military and civilian firms at time $t ; K_{0}$ is the initial technology level. It can be seen that $K(t)$ is an increasing function of diminishing marginal returns. The dual-use technology development function $K(t)$ is bounded when other factors being constant.

The demand function in the process of dual-use technology conversion comprises two parts: national defense demand and economic demand. The demand function can be expressed by Equation (3), where $\lambda$ is the coefficient for military and civilian firms of the national defense demand, and $\theta$ represents the coefficient of economic demand.

$$
Q(t)=\lambda\left[E_{M}(t)+E_{C}(t)\right]+(\lambda+\theta) K(t)
$$

The demand can be reflected in price and non-price factors [33], which can influence the market through separation and multiplication. However, military and civilian enterprises are more supported and constrained by Chinese policies. In this context, the conversion is more supply-oriented from technology than demand-oriented from the market, which indicates that the price elasticity coefficient of demand is not clear. Hence, this article considers the impact of production on demand due to technology growth in the non-price component. Depending on the bureaucratic system represented in state subsidies and accounting procedures [34], domestic defense demand comes from military procurement in China, which has implications for enterprise behavior. Therefore, the demand function 
reflects positive defense demand due to both sides' efforts and dual-use technology development. Economic demand is affected by the technology level. In other words, economic demand is highly sensitive to technical production, which is the non-price factor.

The other factors are shown in Table 1.

Table 1. Notation.

\begin{tabular}{cc}
\hline Notation & Description \\
\hline$M$ & A single military firm \\
$C$ & A single civil firm \\
$E(t)$ & The effort level of dual-use technology conversion \\
$c(t)$ & Conversion cost \\
$K(t)$ & Dual-use technologies level \\
$\mu$ & Cost coefficients \\
$\alpha$ and $\beta$ & Coefficient of technological innovation capability of military and civilian firms \\
$\delta$ & The attenuation coefficient of dual-use technology \\
$Q(t)$ & Total revenue of dual-use technology conversion \\
$\lambda$ & Coefficient of military and civilian firms on the national defense demand \\
$\theta$ & Coefficient of economic demand \\
$t$ & At time $t$ \\
$\rho$ & The discount rate of dual-use technology \\
$\pi$ & The revenue distribution coefficient of civil firm \\
$\eta$ & Subsidy of dual-use technology conversion \\
$J$ & Objective function \\
$V$ & Optimal revenue function \\
$E(K(t))$ & Expectation \\
$D(K(t))$ & Variance \\
$f(x)$ & Brownian motion \\
$B(t)$ & Standard Wiener process \\
$z(t)$ & Random interference factors \\
$\varepsilon$ &
\end{tabular}

The differential game models include three control variables $E_{M}(t), E_{C}(t)$, and $\eta$, and one state variable $K(t)$. Since the model cannot be solved in the non-fixed parameter case, we assume all the model parameters are positive fixed parameters with time irrelevance. Both military and civilian firms face the same game in infinite time. Thus, both players make static decisions and get corresponding static feedback equilibrium in this paper [35].

Based on the above assumptions, we elaborate on three different modes (spin-off, spin-in, and mix) to describe the relationships of military and civilian firms according to three dual-use technology conversion directions.

\section{Equilibrium Analysis}

\subsection{Resolving Models of Spin-Off}

To resolve technical bottlenecks in the civilian field and improve the range and quality of civilian products, the government pushes military firms to undergo conversion, which means using defense technology and facilities to make civilian products (spin-off). In China, the military firm is more easily able to obtain R\&D funds, technological talent, social resources, and faceless political resistance than the civilian firm. The initial technology and applications can be used in the production of the military firm, leading consumers to trust military technology due to its characteristics of high technical content and high reliability. Thus, military technology is competitive in the market. When the military firm enters the civilian market, military and civilian firms form a mutually independent and equally competitive relationship in one market. Both military and civilian firms aim to maximize profits and make independent and rational decisions under the regulation of market mechanisms. This non-cooperative decision-making combination reaches the Nash equilibrium state. Therefore, 
we used the Nash non-cooperative game to describe the mode of spin-off. We combined game theory and differential equations and expressed the objective function that integrates over an infinite time horizon [36]. The objective functions of military and civilian firms can be shown as follows:

$$
\begin{gathered}
J_{M}=\int_{0}^{\infty} e^{-\rho t}\left[(1-\pi) Q(t)-c_{M}\right] d t \\
J_{C}=\int_{0}^{\infty} e^{-\rho t}\left[\pi Q(t)-c_{C}\right] d t
\end{gathered}
$$

where $\rho$ is the discount rate of dual-use technology of the military firm and the civilian firm, $\rho \in(0,1]$. Dockner (2000) [37] indicated that if the end of the planning period in a differential game is unknown or very far in the future, the discounting factor is especially important to discount returns. Military and civilian enterprises aim to maximize efficiency; thus, we use demand, which incurs the benefits from joint production, minus cost to represent the objective function [38].

To achieve the Nash equilibrium in this state, it is assumed that $V_{M}(K)$ and $V_{C}(K)$, which are bounded and continuously differentiable, are optimal revenue functions for military and civilian firms, respectively. With the condition of an infinite time horizon, the bounded optimal function, and the positive discount rate, we can use the Hamilton-Jacobi-Bellman equations to calculate the optimal revenue functions as follows:

$$
\begin{aligned}
& \rho V_{M}(K)=\max _{E_{M} \geq 0}\left\{(1-\pi)\left[\lambda\left(E_{M}+E_{C}+K\right)+\theta K\right]-\frac{\mu_{M}}{2} E_{M}(t)^{2}+V_{M}{ }^{\prime}(K)\left(\alpha E_{M}+\beta E_{C}-\delta K\right)+\frac{\varepsilon^{2}(K)}{2} V_{M}^{\prime \prime}(K)\right\} \\
& \rho V_{C}(K)=\max _{E_{C} \geq 0}\left\{\pi\left[\lambda\left(E_{M}+E_{C}+K\right)+\theta K\right]-\frac{\mu_{C}}{2} E_{C}(t)^{2}+V_{C}^{\prime}(K)\left(\alpha E_{M}+\beta E_{C}-\delta K\right)+\frac{\varepsilon^{2}(K)}{2} V_{C}{ }^{\prime \prime}(K)\right\}
\end{aligned}
$$

For profit maximization, we use extreme conditions and locate the optimal effort for military and civilian firms by setting the first partial derivative equal to zero:

$$
\begin{gathered}
E_{M}=\frac{(1-\pi) \lambda+\alpha V_{M}^{\prime}(K)}{\mu_{M}} \\
E_{C}=\frac{\pi \lambda+\beta V_{C}^{\prime}(K)}{\mu_{C}}
\end{gathered}
$$

Substituting Equation $(6 a, b)$ into $(5 a, b)$, we can get:

$$
\begin{array}{r}
\rho V_{M}(K)=\left[(1-\pi)(\lambda+\theta)-\delta V_{M}^{\prime}(K)\right] K+\frac{\left[(1-\pi) \lambda+\alpha V_{M}^{\prime}(K)\right]^{2}}{2 \mu_{M}}+\frac{\left[(1-\pi) \lambda+\beta V_{M}^{\prime}(K)\right]\left[\pi \lambda+\beta V_{C}^{\prime}(K)\right]}{\mu_{C}} \\
\rho V_{C}(K)=\left[\pi(\lambda+\theta)-\delta V_{C}^{\prime}(K)\right] K+\frac{\left[\pi \lambda+\alpha V_{C}^{\prime}(K)\right]\left[(1-\pi) \lambda+\alpha V_{M}^{\prime}(K)\right]}{\mu_{M}}+\frac{\left[\pi \lambda+\beta V_{C}^{\prime}(K)\right]^{2}}{2 \mu_{C}}
\end{array}
$$

It can be seen that the linear optimal return function for $K$ is the solution of the HJB equation. Let:

$$
V_{M}(K)=m_{1} K+m_{2} V_{C}(K)=n_{1} K+n_{2}
$$

where $m_{1}, m_{2}, n_{1}$, and $n_{2}$ are constant.

After substituting Equation (8) into (7a,b), we can derive $m_{1}, m_{2}, n_{1}$, and $n_{2}$ as follows:

$$
\left\{\begin{array}{l}
m_{1}=\frac{(1-\pi)(\lambda+\theta)}{\rho+\delta} \\
m_{2}=\frac{(1-\pi)^{2}[\lambda(\rho+\delta)+\alpha(\lambda+\theta)]^{2}}{2 \mu_{M}(\rho+\delta)^{2} \rho}+\frac{(1-\pi) \pi[\lambda(\rho+\delta)+\beta(\lambda+\theta)]^{2}}{\mu_{C}(\rho+\delta)^{2} \rho}
\end{array}\right.
$$




$$
\left\{\begin{array}{l}
n_{1}=\frac{\pi(\lambda+\theta)}{\rho+\delta} \\
n_{2}=\frac{\pi(1-\pi)[\lambda(\rho+\delta)+\alpha(\lambda+\theta)]^{2}}{\mu_{M}(\rho+\delta)^{2} \rho}+\frac{\pi^{2}[\lambda(\rho+\delta)+\beta(\lambda+\theta)]^{2}}{2 \mu_{C}(\rho+\delta)^{2} \rho}
\end{array}\right.
$$

We obtain the optimal effort level and optimal revenue function of dual-use technology conversion of military and civilian firms when we substitute $m_{1}, m_{2}, n_{1}$, and $n_{2}$ into Equations $(6 \mathrm{a}, \mathrm{b})$ and (8). The optimal effort level in the model of spin-off can be expressed as follows:

$$
\begin{gathered}
E_{M}^{N}=\frac{(1-\pi)[\lambda(\rho+\delta)+\alpha(\lambda+\theta)]}{\mu_{M}(\rho+\delta)} \\
E_{C}^{N}=\frac{\pi[\lambda(\rho+\delta)+\beta(\lambda+\theta)]}{\mu_{C}(\rho+\delta)}
\end{gathered}
$$

The optimal revenue function for military and civil firms in the model of spin-off can be expressed as follows:

$$
\begin{gathered}
V_{M}^{N}=\frac{(1-\pi)(\lambda+\theta)}{\rho+\delta} K+\frac{(1-\pi)^{2}[\lambda(\rho+\delta)+\alpha(\lambda+\theta)]^{2}}{2 \mu_{M}(\rho+\delta)^{2} \rho}+\frac{(1-\pi) \pi[\lambda(\rho+\delta)+\beta(\lambda+\theta)]^{2}}{\mu_{C}(\rho+\delta)^{2} \rho} \\
V_{C}^{N}=\frac{\pi(\lambda+\theta)}{\rho+\delta} K+\frac{\pi(1-\pi)[\lambda(\rho+\delta)+\alpha(\lambda+\theta)]^{2}}{\mu_{M}(\rho+\delta)^{2} \rho}+\frac{\pi^{2}[\lambda(\rho+\delta)+\beta(\lambda+\theta)]^{2}}{2 \mu_{C}(\rho+\delta)^{2} \rho}
\end{gathered}
$$

The whole optimal revenue function in the CMI system is:

$$
V^{N}=V_{M}(K)+V_{C}(K)=\frac{\lambda+\theta}{\rho+\delta} K+\frac{1-\pi^{2}[\lambda(\rho+\delta)+\alpha(\lambda+\theta)]^{2}}{2 \mu_{M}(\rho+\delta)^{2} \rho}+\frac{\pi(2-\pi)[\lambda(\rho+\delta)+\beta(\lambda+\theta)]^{2}}{2 \mu_{C}(\rho+\delta)^{2} \rho}
$$

We can see that the payoff of military and civilian firms is closely related to the improvement of dual-use technology. To understand the dynamic development of dual-use technology, we use expectation and variance to describe its numeric characteristics. Under the Nash equilibrium, we can obtain the limit of expectation and variance of dual-use technology transfer. The result of substituting Equation $(11 \mathrm{a}, \mathrm{b})$ into Equation $(4 \mathrm{a}, \mathrm{b})$ can be expressed as follows:

$$
\left\{\begin{array}{l}
d K(t)=\left[\Omega^{N}-\delta K(t)\right] d t+\varepsilon(K(t)) d z(t) \\
K(0)=K_{0} \geq 0
\end{array}\right.
$$

where $\Omega^{N}=\frac{\alpha(1-\pi)[\lambda(\rho+\delta)+\alpha(\lambda+\theta)]}{\mu_{M}(\rho+\delta)}+\frac{\beta \pi[\lambda(\rho+\delta)+\beta(\lambda+\theta)]}{\mu_{C}(\rho+\delta)}$. For further analysis, let $\varepsilon(K(t)) d z(t)=\varepsilon \sqrt{K} d z(t)$.

We can use Itô's lemma to find the differential of a time-dependent function of a stochastic process. When $t \in \forall$, Itô's lemma assumes $f(x)$ is a quadratic continuous differential function; thus, Itô's equation is expressed as:

$$
f(B(t))=f(0)+\int_{0}^{t} f^{\prime}(B(s)) d B(s)+\frac{\int_{0}^{t} f^{\prime}(B(s)) d s}{2}
$$

where $B(t)$ is Brownian motion.

According to Itô's lemma and Equation (13), we can get

$$
\left\{\begin{array}{l}
d(K(t))^{2}=\left[\left(2 \Omega^{N}+\varepsilon^{2}\right) K-2 \delta K\right] d t+2 K \varepsilon \sqrt{K} d z(t) \\
(K(0))^{2}=\left(K_{0}\right)^{2}
\end{array}\right.
$$


Hence, the expectation $E(K(t))$ and expectation squared $E(K(t))^{2}$ of the dual-use technology level satisfy the non-homogeneous linear differential equations as follows:

$$
\begin{gathered}
\left\{\begin{array}{l}
d E(K(t))=\left[\Omega^{N}-\delta E(K)\right] d t \\
E(K(0))=K_{0}
\end{array}\right. \\
\left\{\begin{array}{l}
d E(K(t))^{2}=\left[\left(\Omega^{N}+\varepsilon^{2}\right) E(K)-2 \delta E\left(K^{2}\right)\right] d t \\
E(K(0))^{2}=\left(K_{0}\right)^{2}
\end{array}\right.
\end{gathered}
$$

Then the limit of expectation and variance can be expressed as follows:

$$
\begin{gathered}
E\left[K^{N}(t)\right]=\frac{\Omega^{N}}{\delta}+e^{-\delta t}\left(K_{0}-\frac{\Omega^{N}}{\delta}\right), \lim _{t \rightarrow \infty} E\left[K^{N}(t)\right]=\frac{\Omega^{N}}{\delta} \\
D\left[K^{N}(t)\right]=\frac{\varepsilon^{2}\left[\Omega^{N}-2\left(\Omega^{N}-\delta K_{0}\right) e^{-\delta t}+\left(\Omega^{N}-2 \delta K_{0}\right) e^{-2 \delta t}\right]}{2 \delta^{2}}, \lim _{t \rightarrow \infty} D\left[K^{N}(t)\right]=\frac{\varepsilon^{2} \Omega^{N}}{2 \delta^{2}}
\end{gathered}
$$

\subsection{Resolving Models of Spin-In}

In recent decades, by the implementation of supporting facilities of weaponry or subcontracting scientific research and production tasks, the civilian firm has enthusiastically participated in the CMI (spin-in). Rapid socio-economic development and the accelerating speed of technology upgrades have allowed numerous civilian firms to obtain core technologies and make breakthroughs in high-tech fields. In addition, the stable demand and high profits of the military market have encouraged the civilian firm to actively participate in the CMI program. For the military firm, the introduction of advanced civilian technology can mitigate the pressure associated with the high risk of R\&D and long production cycles.

In the model of spin-in, the relationship between a military firm and a civilian firm can be ideally explained by a Stackelberg differential game dominated by the military firm. We consider the situation in which the military firm can commit to the effort level of dual-use technology transfer and subsidies for the civilian firm. Then, the civilian firm can observe the strategy of the military firm and decide its own strategy. In the Stackelberg differential game, the military firm is the leader who needs to satisfy their interests and the demand for national defense, and the civilian firm is the follower who aims to maximize their benefits. It is assumed that both the military and civilian firms can obtain complete information and potential opponents' strategies. The partial differential equations can express the objective functions of the military and civilian firms, respectively, as follows:

$$
\begin{gathered}
J_{M}=\int_{0}^{\infty} e^{-\rho t}\left[(1-\pi) Q(t)-c_{M}-\eta c_{C}\right] d t \\
J_{C}=\int_{0}^{\infty} e^{-\rho t}\left[\pi Q(t)-(1-\eta) c_{C}\right] d t
\end{gathered}
$$

where $\eta \in[0,1]$ is the subsidies factor from the military firm to civilian firm; $\rho \in(0,1]$ is the discount rate of dual-use technology.

To obtain the Stackelberg equilibrium, it is assumed that $V_{M}(K)$ and $V_{C}(K)$ are optimal revenue functions for military and civilian firms, respectively, which are bounded and continuously differentiable. Hamilton-Jacobi-Bellman equations are used to calculate the optimal revenue function of the civilian firm as follows:

$$
\rho V_{C}(K)=\max _{E_{C} \geq 0}\left\{\pi\left[\lambda\left(E_{M}+E_{C}+K\right)+\theta K\right]-(1-\eta) \frac{\mu_{C}}{2} E_{C}(t)^{2}+V_{C}^{\prime}(K)\left(\alpha E_{M}+\beta E_{C}-\delta K\right)+\frac{\varepsilon^{2}(K)}{2} V_{C}^{\prime \prime}(K)\right\}
$$


The optimal effort level of dual-use technology conversion can be computed by setting the first partial derivative equal to zero, and the civilian firm's optimal effort level can be expressed as follows:

$$
E_{C}=\frac{\pi \lambda+\beta V_{C}^{\prime}(K)}{(1-\eta) \mu_{C}}
$$

The military firm predicts the civilian firm's effort level with historical information and a rational reaction to decide on its dual-use technology conversion effort and the size of the subsidy factor. Hamilton-Jacobi-Bellman equations are used to calculate the optimal revenue function of military firms as follows:

$$
\rho V_{M}(K)=\max _{E_{M} \geq 0}\left\{(1-\pi)\left[\lambda\left(E_{M}+E_{C}+K\right)+\theta K\right]-\frac{\mu_{M}}{2} E_{M}(t)^{2}-\eta \frac{\mu_{C}}{2} E_{C}(t)^{2}+V_{M}^{\prime}(K)\left(\alpha E_{M}+\beta E_{C}-\delta K\right)+\frac{\varepsilon^{2}(K)}{2} V_{M}^{\prime}(K)\right.
$$

$E_{M}$ and $\eta$ can be calculated by setting the first partial derivative equal to zero, to give:

$$
\begin{gathered}
E_{M}=\frac{(1-\pi) \lambda+\alpha V_{M}^{\prime}(K)}{\mu_{M}} \\
\eta=\frac{\lambda(2-3 \pi)+\beta\left[2 V_{M}^{\prime}(K)-V_{C}^{\prime}(K)\right]}{\lambda(2-\pi)+\beta\left[2 V_{M}^{\prime}(K)+V_{C}^{\prime}(K)\right]}
\end{gathered}
$$

The results of substituting Equations (21), (23), and (24) into Equations (20) and (22) can be expressed as follows:

$$
\begin{gathered}
\rho V_{M}(K)=\left[(1-\pi)(\lambda+\theta)-\delta V_{M}^{\prime}(K)\right] K+\frac{\left[(1-\pi) \lambda+\alpha V_{M}^{\prime}(K)\right]^{2}}{2 \mu_{M}}+\frac{\left\{\lambda(2-\pi)+\beta\left[2 V_{M}^{\prime}(K)+V_{C}^{\prime}(K)\right]\right\}^{2}}{8 \mu_{C}} \\
\rho V_{C}(K)=\left[\pi(\lambda+\theta)-\delta V_{C}^{\prime}(K)\right] K+\frac{\left[(1-\pi) \lambda+\alpha V_{M}^{\prime}(K)\right]\left[\pi \lambda+\alpha V_{C}^{\prime}(K)\right]}{\mu_{M}} \\
+\frac{\left\{\lambda(2-\pi)+\beta\left[2 V_{M}^{\prime}(K)+V_{C}^{\prime}(K)\right]\right\}\left[\pi \lambda+\beta V_{C}^{\prime}(K)\right]}{4 \mu_{C}}
\end{gathered}
$$

It can be seen that the linear optimal return function for $K$ is the solution of the HJB equation. Let

$$
V_{M}(K)=f_{1} K+f_{2} V_{C}(K)=g_{1} K+g_{2}
$$

where $f_{1}, f_{2}, g_{1}$, and $g_{2}$ are constant.

After substituting Equation (26) into Equation (25a,b), we can obtain $f_{1}, f_{2}, g_{1}$, and $g_{2}$ as follows:

$$
\begin{aligned}
& \left\{\begin{array}{l}
f_{1}=\frac{(1-\pi)(\lambda+\theta)}{\rho+\delta} \\
f_{2}=\frac{(1-\pi)^{2}[\lambda(\rho+\delta)+\alpha(\lambda+\theta)]^{2}}{2 \mu_{M}(\rho+\delta)^{2} \rho}+\frac{(2-\pi)^{2}[\lambda(\rho+\delta)+\beta(\lambda+\theta)]^{2}}{8 \mu_{C}(\rho+\delta)^{2} \rho}
\end{array}\right. \\
& \left\{\begin{array}{l}
g_{1}=\frac{\pi(\lambda+\theta)}{\rho+\delta} \\
g_{2}=\frac{\pi(1-\pi)[\lambda(\rho+\delta)+\alpha(\lambda+\theta)]^{2}}{\mu_{M}(\rho+\delta)^{2} \rho}+\frac{\pi(2-\pi)[\lambda(\rho+\delta)+\beta(\lambda+\theta)]^{2}}{4 \mu_{C}(\rho+\delta)^{2} \rho}
\end{array}\right.
\end{aligned}
$$

Hence, the optimal effort level and subsidies factor in the model of spin-in can be expressed as follows:

$$
E_{M}^{S}=\frac{(1-\pi)[\lambda(\rho+\delta)+\alpha(\lambda+\theta)]}{\mu_{M}(\rho+\delta)}
$$




$$
\begin{gathered}
E_{C}^{S}=\frac{(2-\pi)[\lambda(\rho+\delta)+\beta(\lambda+\theta)]}{2 \mu_{C}(\rho+\delta)} \\
\eta=\left\{\begin{array}{c}
\frac{2-3 \pi}{2-\pi}, 0<\pi<\frac{2}{3} \\
0, \frac{2}{3}<\pi<1
\end{array}\right.
\end{gathered}
$$

The optimal revenue functions for military and civilian firms in the model of spin-in can be expressed as follows:

$$
\begin{gathered}
V_{M}^{S}=\frac{(1-\pi)(\lambda+\theta)}{\rho+\delta} K+\frac{(1-\pi)^{2}[\lambda(\rho+\delta)+\alpha(\lambda+\theta)]^{2}}{2 \mu_{M}(\rho+\delta)^{2} \rho}+\frac{(2-\pi)^{2}[\lambda(\rho+\delta)+\beta(\lambda+\theta)]^{2}}{8 \mu_{C}(\rho+\delta)^{2} \rho} \\
V_{C}^{S}=\frac{\pi(\lambda+\theta)}{\rho+\delta} K+\frac{\pi(1-\pi)[\lambda(\rho+\delta)+\alpha(\lambda+\theta)]^{2}}{\mu_{M}(\rho+\delta)^{2} \rho}+\frac{\pi(2-\pi)[\lambda(\rho+\delta)+\beta(\lambda+\theta)]^{2}}{4 \mu_{C}(\rho+\delta)^{2} \rho}
\end{gathered}
$$

The whole optimal revenue function of spin-in in the CMI system is:

$$
V^{S}=\frac{\lambda+\theta}{\rho+\delta} K+\frac{\left(1-\pi^{2}\right)[\lambda(\rho+\delta)+\alpha(\lambda+\theta)]^{2}}{2 \mu_{M}(\rho+\delta)^{2} \rho}+\frac{\left(4-\pi^{2}\right)[\lambda(\rho+\delta)+\beta(\lambda+\theta)]^{2}}{8 \mu_{C}(\rho+\delta)^{2} \rho}
$$

Under the Stackelberg equilibrium, we can obtain the limit of expectation and variance dual-use technology level. The proof process is the same as that of the spin-off model. The limit of expectation and variance are shown as follows:

$$
\begin{gathered}
E\left[K^{S}(t)\right]=\frac{\Omega^{S}}{\delta}+e^{-\delta t}\left(K_{0}-\frac{\Omega^{S}}{\delta}\right), \lim _{t \rightarrow \infty} E\left[K^{S}(t)\right]=\frac{\Omega^{S}}{\delta} \\
D\left[K^{S}(t)\right]=\frac{\varepsilon^{2}\left[\Omega^{S}-2\left(\Omega^{S}-\delta K_{0}\right) e^{-\delta t}+\left(\Omega^{S}-2 \delta K_{0}\right) e^{-2 \delta t}\right]}{2 \delta^{2}}, \lim _{t \rightarrow \infty} D\left[K^{S}(t)\right]=\frac{\varepsilon^{2} \Omega^{S}}{2 \delta^{2}}
\end{gathered}
$$

where $\Omega^{S}=\frac{(1-\pi) \alpha[\lambda(\rho+\delta)+\alpha(\lambda+\theta)]}{\mu_{M}(\rho+\delta)}+\frac{(2-\pi) \beta[\lambda(\rho+\delta)+\beta(\lambda+\theta)]}{2 \mu_{C}(\rho+\delta)}$.

\subsection{Resolving Models of Mix}

The mode of mix means a military firm and a civilian firm produce dual-use technology, which requires the military firm and the civilian firm to have similar characteristics, including market demand, technology standards, and equipment performance. Dual-use technologies meet both the high standards characteristic of military technology and the practical applicability of civilian technology. In mix mode, the relationship between a military firm and a civilian firm is complicated and includes competition and cooperation. The maximization of overall utility is the common goal for both sides. Both firms can choose their optimal effort levels and share the revenue function of dual-use technology conversion based on the maximization of their total payoff. Therefore, we chose the cooperative game to describe this model. We can assume that the objective function of Mix is:

$$
J=J_{M}+J_{C}=\int_{0}^{\infty} e^{-\rho t}\left[Q(t)-c_{M}-c_{C}\right] d t
$$

where $\rho \in(0,1]$ is the discount rate of dual-use technology.

To obtain the equilibrium of the cooperative game, it is assumed that $V(K)$ is the optimal revenue function, which is bounded and continuously differentiable. Hamilton-Jacobi-Bellman equation is used to calculate the optimal revenue function:

$$
\rho V(K)=\max _{E_{M} E_{C}}\left\{\lambda\left[\left(E_{M}+E_{C}+K\right)+\theta K\right]-\frac{\mu_{M}}{2} E_{M}(t)^{2}-\frac{\mu_{C}}{2} E_{C}(t)^{2}+V^{\prime}(K)\left(\alpha E_{M}+\beta E_{C}-\delta K\right)+\frac{\varepsilon^{2}(K)}{2} V^{\prime \prime}(K)\right\}
$$


To maximize profits, we use extreme conditions and search for the optimal effort of military and civilian firms by setting the first partial derivative equal to zero, to give:

$$
\begin{aligned}
& E_{M}=\frac{\lambda+\alpha V^{\prime}(K)}{\mu_{M}} \\
& E_{C}=\frac{\lambda+\beta V^{\prime}(K)}{\mu_{C}}
\end{aligned}
$$

By substituting the results of $(35 a, b)$ into $(34)$, we can get:

$$
\rho V(K)=\left[\lambda+\theta-\delta V^{\prime}(K)\right] K+\frac{\left[\lambda+\alpha V^{\prime}(K)\right]^{2}}{2 \mu_{M}}+\frac{\left[\lambda+\beta V^{\prime}(K)\right]^{2}}{2 \mu_{C}}+\frac{\varepsilon^{2}(K)}{2} V^{\prime \prime}(K)
$$

The solution of the HJB equation is a linear optimal return function for $K$ as an independent variable. Let:

$$
V(K)=h_{1} K+h_{2}
$$

where $h_{1}$ and $h_{2}$ are constant.

Substituting Equation (37) into Equation (36) gives:

$$
\left\{\begin{array}{l}
h_{1}=\frac{\lambda+\theta}{\rho+\delta} \\
h_{2}=\frac{[\lambda(\rho+\delta)+\alpha(\lambda+\theta)]^{2}}{2 \mu_{M}(\rho+\delta)^{2} \rho}+\frac{[\lambda(\rho+\delta)+\beta(\lambda+\theta)]^{2}}{2 \mu_{C}(\rho+\delta)^{2} \rho}
\end{array}\right.
$$

Hence, the optimal effort level and subsidy factor in the mix model can be expressed as follows:

$$
\begin{aligned}
& E_{M}^{C}=\frac{\lambda(\rho+\delta)+\alpha(\lambda+\theta)}{\mu_{M}(\rho+\delta)} \\
& E_{C}^{C}=\frac{\lambda(\rho+\delta)+\beta(\lambda+\theta)}{\mu_{C}(\rho+\delta)}
\end{aligned}
$$

The overall optimal revenue function for the military firm and the civilian firm in the mix model can be expressed as follows:

$$
V^{C}=\frac{\lambda+\theta}{\rho+\delta} K+\frac{[\lambda(\rho+\delta)+\alpha(\lambda+\theta)]^{2}}{2 \mu_{M}(\rho+\delta)^{2} \rho}+\frac{[\lambda(\rho+\delta)+\beta(\lambda+\theta)]^{2}}{2 \mu_{C}(\rho+\delta)^{2} \rho}
$$

Under a cooperative equilibrium, we can obtain the limit of expectation and variance of the dual-use technology level. The proof process is the same as that for Equations (13)-(16). The limits of expectation and variance can be expressed as:

$$
\begin{gathered}
E\left[K^{C}(t)\right]=\frac{\Omega^{C}}{\delta}+e^{-\delta t}\left(K_{0}-\frac{\Omega^{C}}{\delta}\right), \lim _{t \rightarrow \infty} E\left[K^{C}(t)\right]=\frac{\Omega^{C}}{\delta} \\
D\left[K^{N}(t)\right]=\frac{\varepsilon^{2}\left[\Omega^{C}-2\left(\Omega^{C}-\delta K_{0}\right) e^{-\delta t}+\left(\Omega^{C}-2 \delta K_{0}\right) e^{-2 \delta t}\right]}{2 \delta^{2}}, \lim _{t \rightarrow \infty} D\left[K^{N}(t)\right]=\frac{\varepsilon^{2} \Omega^{C}}{2 \delta^{2}}
\end{gathered}
$$

where $\Omega^{C}=\frac{\alpha[\lambda(\rho+\delta)+\alpha(\lambda+\theta)]}{\mu_{M}(\rho+\delta)}+\frac{\beta[\lambda(\rho+\delta)+\beta(\lambda+\theta)]}{\mu_{C}(\rho+\delta)}$. 


\section{Comparative Analysis of Equilibrium Results}

\subsection{Comparative Analysis of Equilibrium Results of Optimal Effort Level}

According to the above derivation of dual-use technology conversion between the military firm and the civilian firm in the three models, we can demonstrate the comparative analysis of the equilibrium results of the optimized effort levels as follows:

$$
\begin{gathered}
E_{M}^{S}-E_{M}^{N}=0 \\
E_{M}^{C}-E_{M}^{S}=\frac{\pi[\lambda(\rho+\delta)+\alpha(\lambda+\theta)]}{\mu_{M}(\rho+\delta)} \\
E_{C}^{S}-E_{C}^{N}=\frac{(2-3 \pi)[\lambda(\rho+\delta)+\beta(\lambda+\theta)]}{2 \mu_{C}(\rho+\delta)}=\frac{(2-\pi)[\lambda(\rho+\delta)+\beta(\lambda+\theta)]}{2 \mu_{C}(\rho+\delta)} \times \frac{2-3 \pi}{2-\pi}=E_{C}^{S} \times \eta^{*}>0 \\
E_{C}^{C}-E_{C}^{S}=\frac{\pi[\lambda(\rho+\delta)+\beta(\lambda+\theta)]}{2 \mu_{C}(\rho+\delta)}
\end{gathered}
$$

According to $0<\pi<\frac{2}{3}$, we can obtain $E_{M}^{C}>E_{M}^{S}=E_{M}^{N}$ and $E_{C}^{C}>E_{C}^{S}>E_{C}^{N}$. The military and civilian firms achieve the highest effort level in the mix mode. The military firm has the same effort level in spin-off and spin-in modes. The effort level of the civilian firm is improved in spin-in compared with spin-off. It can be seen that the degree of improvement is equal to the best subsidies factor from the military firm to the civilian firm; this indicates that subsidies are an incentive mechanism that encourages the civil firm to make a greater effort towards technology transfer.

\subsection{Comparative Analysis of Equilibrium Results of Optimal Revenue}

We find that the optimal revenue of dual-use technology conversion in the equilibrium results of spin-in is better than in spin-off for both firms.

$$
\begin{gathered}
V_{M}^{S}-V_{M}^{N}=\frac{(2-3 \pi)^{2}[\lambda(\rho+\delta)+\beta(\lambda+\theta)]^{2}}{8 \mu_{C}(\rho+\delta)^{2} \rho} \\
V_{C}^{S}-V_{C}^{N}=\frac{\pi(2-3 \pi)[\lambda(\rho+\delta)+\beta(\lambda+\theta)]}{4 \mu_{C}(\rho+\delta)^{2} \rho} \\
V^{C}-V^{S}=\frac{\pi^{2}[\lambda(\rho+\delta)+\alpha(\lambda+\theta)]^{2}}{2 \mu_{M}(\rho+\delta)^{2} \rho}+\frac{\pi^{2}[\lambda(\rho+\delta)+\beta(\lambda+\theta)]^{2}}{8 \mu_{C}(\rho+\delta)^{2} \rho}>0 \\
V^{S}-V^{N}=\frac{(2-\pi)(2-3 \pi)[\lambda(\rho+\delta)+\beta(\lambda+\theta)]^{2}}{8 \mu_{C}(\rho+\delta)^{2} \rho}>0
\end{gathered}
$$

According to $0<\pi<\frac{2}{3}$, the order of total revenue is $V^{C}>V^{S}>V^{N}$. This indicates that the overall system can achieve the best payoff when military and civilian firms cooperate to undertake the bidirectional dual-use technology conversion. Furthermore, the overall system in the spin-in mode under the Stackelberg equilibrium condition has the second-highest payoff.

\subsection{Dual-Use Technology Development}

Comparing the expectation and variance of the improvement degree of the dual-use technology level in the three modes allows measurement of the stability of the technology development in the conversion. The comparing process is as follows:

$$
E\left[K^{S}(t)\right]-E\left[K^{N}(t)\right]=\frac{1}{\delta}\left(1-e^{-\delta t}\right)\left(\Omega^{S}-\Omega^{N}\right)>0
$$




$$
\lim _{t \rightarrow \infty} E\left[K^{S}(t)\right]-\lim _{t \rightarrow \infty} E\left[K^{N}(t)\right]=\frac{1}{\delta}\left(\Omega^{S}-\Omega^{N}\right)>0
$$

Similarly, we can get

$$
\begin{gathered}
E\left[K^{C}(t)\right]-E\left[K^{S}(t)\right]=\frac{1}{\delta}\left(1-e^{-\delta t}\right)\left(\Omega^{C}-\Omega^{S}\right)>0 \\
\lim _{t \rightarrow \infty} E\left[K^{C}(t)\right]-\lim _{t \rightarrow \infty} E\left[K^{S}(t)\right]=\frac{1}{\delta}\left(\Omega^{C}-\Omega^{S}\right)>0 \\
\lim _{t \rightarrow \infty} D\left[K^{S}(t)\right]-\lim _{t \rightarrow \infty} D\left[K^{N}(t)\right]=\frac{\varepsilon^{2}}{2 \delta^{2}}\left(\Omega^{S}-\Omega^{N}\right)>0 \\
D\left[K^{S}(t)\right]-D\left[K^{N}(t)\right]=\frac{\varepsilon^{2}\left(1-2 e^{-\delta t}+e^{-2 \delta t}\right)}{2 \delta^{2}}\left(\Omega^{S}-\Omega^{N}\right)
\end{gathered}
$$

The first derivative of $1-2 e^{-\delta t}+e^{-2 \delta t}$ is greater than 0 for $t \in(0, \infty) .1-2 e^{-\delta t}+e^{-2 \delta t}=0$ can be obtained by $t \rightarrow 0$, and $D\left[K^{S}(t)\right]>D\left[K^{N}(t)\right]$ can then be obtained. Similarly, $D\left[K^{C}(t)\right]>D\left[K^{S}(t)\right]$ can be obtained. Thus, there exists:

$$
\left\{\begin{array}{l}
E\left[K^{C}(t)\right]>E\left[K^{S}(t)\right]>E\left[K^{N}(t)\right], \lim _{t \rightarrow \infty} E\left[K^{C}(t)\right]>>\lim _{t \rightarrow \infty} E\left[K^{S}(t)\right]>\lim _{t \rightarrow \infty} E\left[K^{N}(t)\right] \\
D\left[K^{C}(t)\right]>D\left[K^{S}(t)\right]>D\left[K^{N}(t)\right], \lim _{t \rightarrow \infty} D\left[K^{C}(t)\right]>\lim _{t \rightarrow \infty} D\left[K^{S}(t)\right]>\lim _{t \rightarrow \infty} D\left[K^{N}(t)\right]
\end{array}\right.
$$

This indicates that the mix mode can develop dual-use technology more readily than the other two modes, followed by the spin-in mode. In contrast, the greater the improvement of dual-use technology, the less the stability achieved by the firms. When the military firm and the civilian firm cooperate and jointly develop dual-use technology, they are subject to more risk and random interference factors. This illustrates that dual-use technology development is significantly influenced by the mode of conversion on increment and stability.

In the collaborative environment, both military and civilian firms make decisions with the goal of overall system optimization, which can decrease the threshold of conversion, advance the efficiency of technology innovation, and ultimately maximize the total benefits. Therefore, the mix mode can reach Pareto optimality in terms of the effort, the revenue, and the technology development.

\section{Simulation and Discussion}

\subsection{Generic Simulation}

To illustrate the theoretical results, we conducted a numerical analysis. The values of the parameters are shown in Table 2. The results under the three game models, in terms of the effort of military and civilian participants, and each optimal revenue level, are shown in Table 3.

Table 2. Fixed parameter initialization setting.

\begin{tabular}{ccccccccccc}
\hline Notation & $\alpha$ & $\boldsymbol{\beta}$ & $\boldsymbol{\rho}$ & $\boldsymbol{\delta}$ & $\boldsymbol{\lambda}$ & $\boldsymbol{\theta}$ & $\mu_{M}$ & $\mu_{C}$ & $\boldsymbol{\pi}$ & $\boldsymbol{\eta}$ \\
\hline Initialization Settings & 0.8 & 0.6 & 0.95 & 0.1 & 0.7 & 0.6 & 0.5 & 0.5 & 0.5 & 0.333 \\
\hline
\end{tabular}

Table 3. Comparison of the results for the three game cases.

\begin{tabular}{cccc}
\hline & Spin-Off & Spin-In & Mix \\
\hline$E_{M}$ & 1.690 & 1.690 & 3.381 \\
$E_{C}$ & 1.443 & 2.536 & 2.886 \\
$V_{M}$ & $0.619 \mathrm{~K}+1.848$ & $0.619 \mathrm{~K}+2.075$ & $0.619 \mathrm{~K}+2.136$ \\
$V_{C}$ & $0.619 \mathrm{~K}+2.052$ & $0.619 \mathrm{~K}+2.324$ & $0.619 \mathrm{~K}+2.136$ \\
$V$ & $1.238 \mathrm{~K}+3.90$ & $1.238 \mathrm{~K}+4.31$ & $1.238 \mathrm{~K}+4.271$ \\
\hline
\end{tabular}


From Table 3, the differences between the military firm and the civilian firm in the cases of spin-off, spin-in, and mix modes can be examined. The effort levels for both firms were improved sequentially by the three modes. This is particularly the case for the civilian firm; civilian revenue was higher than that of military participants in all three cases. Moreover, the total revenue was highest when the firms chose the spin-in mode.

\subsection{Dual-Use Technology Development in Three Modes}

According to Equation (50), dual-use technology development in the three modes differs and improves with the order of spin-off, spin-in, and mix. Simulations of the technology development over time under the three differential games were investigated, as shown in Figure 2. We can see that the steady-state of dual-use technological development was consistent with the model derivation. Dual-use technology growth started at a similar point; then, the rate of technological development led to differentiation, and eventually, to a steady-state. The mix mode grows fastest, at a rate double that of spin-off, and takes twice as long to reach a steady-state as the other two modes. Over time, technological growth eventually reaches a steady-state in which mix has the highest degree of technological development, followed by spin-in. Spin-off has the lowest degree of development.

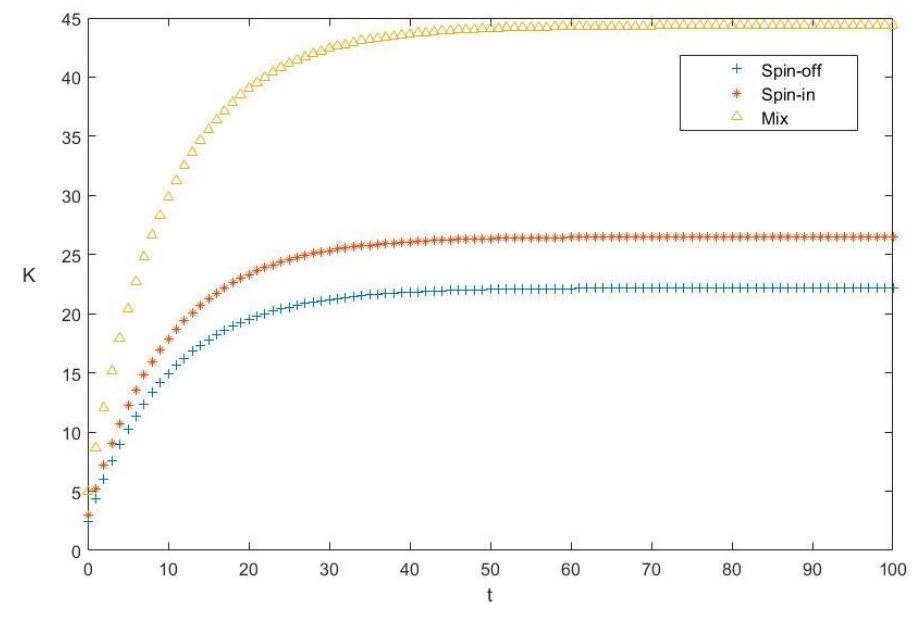

Figure 2. Knowledge development degree in the three modes.

\subsection{Individual and Total Revenue in Three Modes}

According to Equations (45) and (46), revenue for each of the firms, military and civilian, and total revenue, were consistent with the simulation, as shown in Figure 3. The ultimate benefits for both military and civilian firms grow and ultimately reach a steady-state. Mix is the optimal choice to maximize income for both military and civilian firms and in the context of overall returns. These trends were also consistent with the growth of dual-use technologies. All three models of the CMI effectively contribute to an increase in both firms' earnings, and there is a positive correlation between the increase in earnings and the state of technological development. 


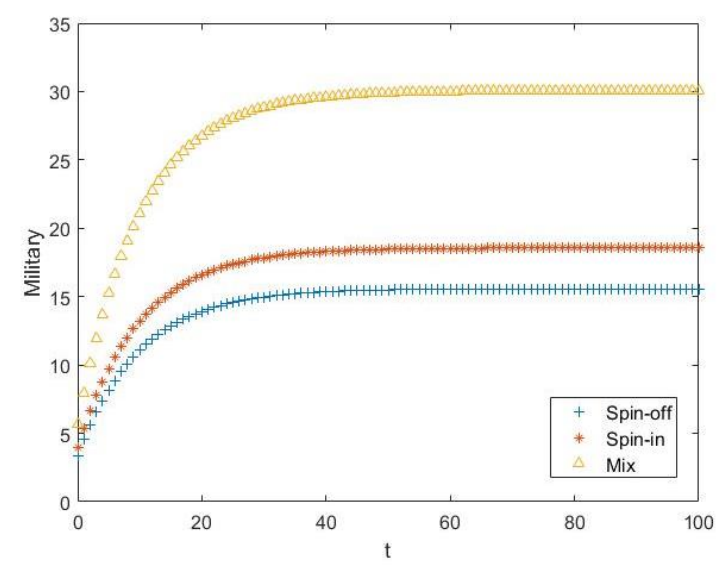

(a)

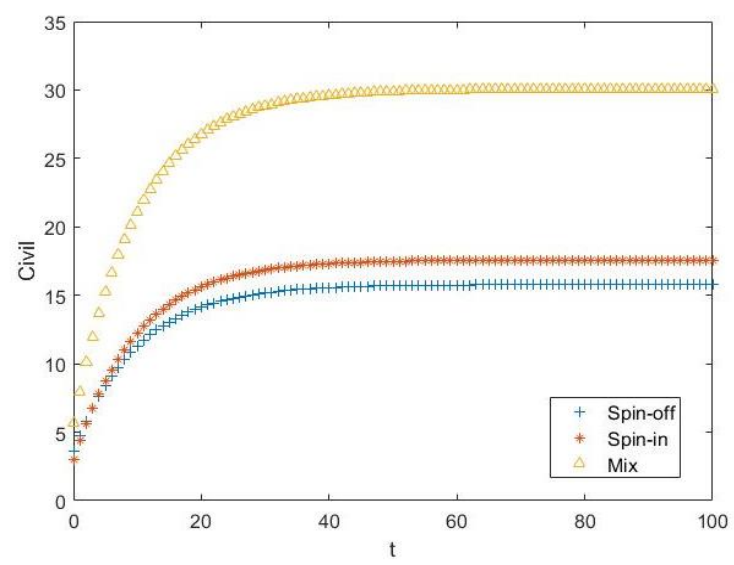

(b)

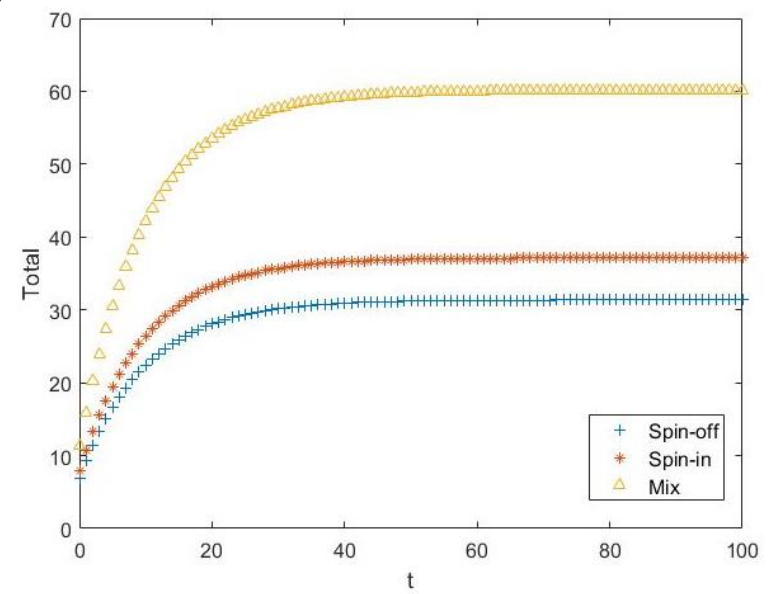

(c)

Figure 3. (a) Military revenue changes with time; (b) civilian revenue changes with time; (c) total revenue changes with time.

\subsection{Revenue Comparison between Military and Civil Firms}

Both military and civilian firms improve overall earnings. However, there is a gap between the two firms' earnings in the same model, shown in Figure 4. In spin-off, the changes in the trajectory of revenues for the military firm and the civilian firm almost overlap, with the military firm earning slightly less than the civilian firm. This suggests that military technology's entry into the civilian sector has a similar catalytic effect on the increase in income for both military and civilian enterprises. The revenue in spin-in is significantly higher than that in spin-off. Furthermore, the profit of the military firm is significantly higher than that of the civilian firm. The entry of civilian technology into the military goods market not only relieves the pressure on the R\&D and production of the defense industry but also stimulates the vitality of the defense market. In mix, because the distribution coefficients were set equally in this study, the earnings trends for military and civilian firms are identical. 


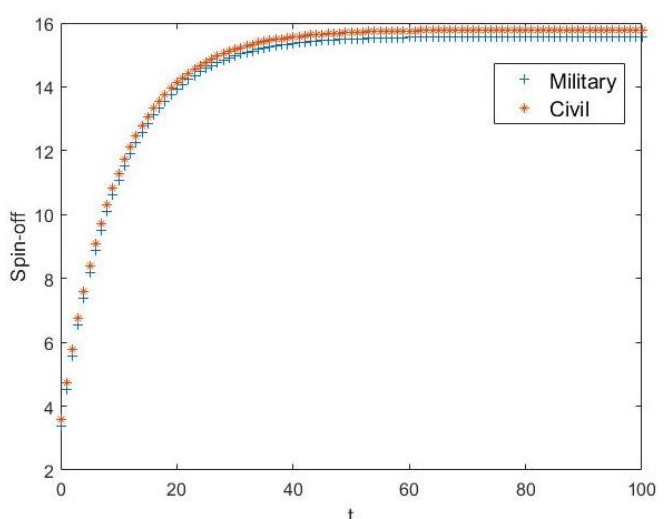

(a)

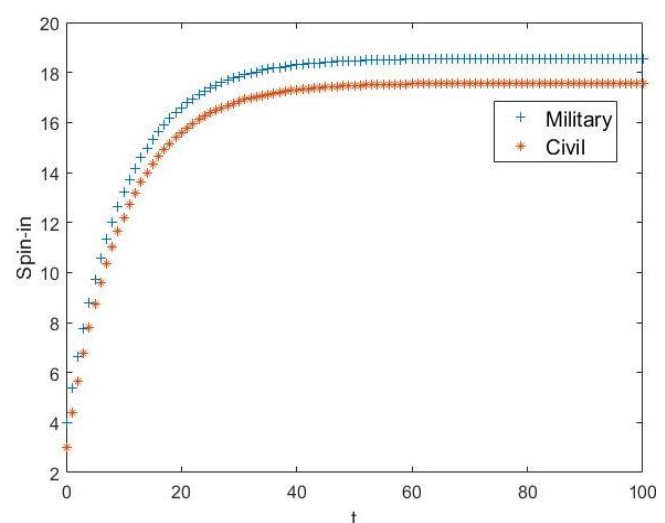

(b)

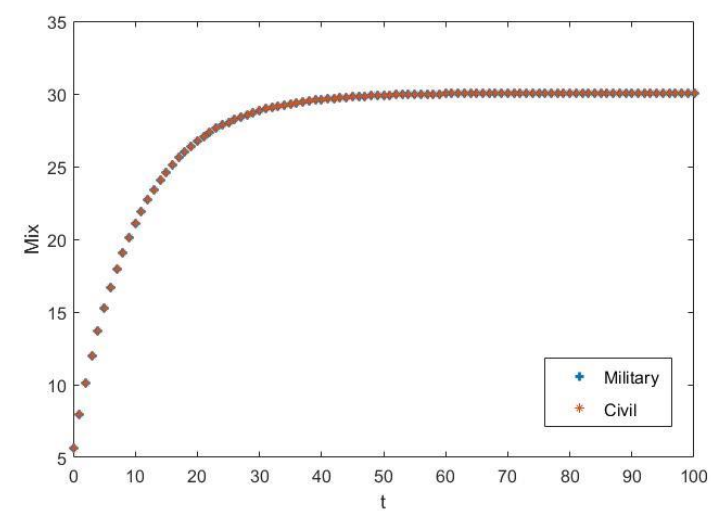

(c)

Figure 4. Military and civil revenue in (a) spin-off, (b) spin-in, and (c) mix.

\section{Conclusions}

In this work, we sought to establish a theoretical model for dual-use technology conversion in civil-military integration. Unlike previous studies, we classified three dual-use technology transfer modes, and more importantly, incorporated the dynamic development of dual-use technology into a unified research framework. We developed a stochastic differential game of dual-use technology conversion between a military firm and a civilian firm in the CMI. By considering the directions of dual-use technology transfer, we used the Nash non-cooperative game, Stackelberg game, and cooperative game to represent dual-use technology conversion in the modes of spin-off, spin-in, and mix, respectively.

By analyzing and comparing the three methods, we identified apparent differences in the transfer efforts, ultimate benefits, and technological development of dual-use technology conversion. The equilibrium and simulation results indicate the following: First, the Pareto optimal results are shown in the decreasing order of mix, spin-in, spin-off, for effort level; individual and total revenue for the military firm and the civilian firm; and dual-use technology development. Second, the military firm earns more than the civilian firm only in spin-in. Third, the greater the technological growth of one mode, the greater the potential instability faced by the firms. In addition, the other findings highlight that: (a) the optimal effort level has a positive correlation with the coefficient of technological innovation capability and a negative correlation with cost coefficients; and (b) the subsidies factor from the military firm can stimulate the civilian firm's efforts.

From the above results, military and civilian firms should choose the mix model for maximizing overall benefits and technological development. However, choosing this model implies more effort from both firms, which means more costs are required. It is also necessary to consider the instability caused by technological development. Therefore, we propose several conclusions. First, enhancing the 
capability for technological innovation and lowering the associated cost is becoming essential. Second, examining and controlling the risk-added problem caused by the value-added in the CMI to ensure the stable development of dual-use technology. Moreover, because subsidies can influence the civilian firm's choice, the military firm can adjust subsidy factors to support the civilian firm's initiative according to their own needs.

However, some limitations in this paper are worth noting. These theoretical models only consider dual-use technology conversion between the military and civilian firms and do not examine the government's role in guiding and promoting CMI. This issue warrants further study in the future.

Author Contributions: Conceptualization, X.Y.; methodology, X.Y.; software, L.Z.; validation, X.C., X.Y. and L.Z.; formal analysis, X.Y.; investigation, X.C. and X.Y.; resources, X.C. and L.Z.; data curation, X.Y.; writing-original draft, X.Y.; preparation, X.Y.; writing-review and editing, X.C., X.Y. and L.Z.; visualization, X.Y.; supervision, X.C.; project administration, X.C.; funding acquisition, X.C. and L.Z. All authors have read and agreed to the published version of the manuscript.

Funding: This research was funded by the National Natural Science Foundation of China (grant number 71473055, 71804084), the Fundamental Research Funds for the Central Universities (grant number 3072020CFW0902), and the Heilongjiang Province Philosophy and Social Science Research Project (grant number 19GLH045).

Conflicts of Interest: The authors declare no conflict of interest.

Data Availability: This article used the mathematical model and analysis without any real data.

\section{References}

1. Cowan, R.; Foray, D. Quandaries in the economics of dual technologies and spillovers from military to civilian research and development. Res. Policy 1995, 24, 851-868. [CrossRef]

2. Hausken, K.; Moxnes, J.F. Innovation, Development and National Indices. Soc. Indic. Res. 2018, 141, 1165-1188. [CrossRef]

3. Furuoka, F.; Oishi, M.; Karim, M.A. Military expenditure and economic development in China: An empirical inquiry. Def. Peace Econ. 2014, 27, 137-160. [CrossRef]

4. Kulve, H.T.; Smit, W.A. Civilian-military co-operation strategies in developing new technologies. Res. Policy 2003, 32, 955-970. [CrossRef]

5. Jing, R.; Benner, M. Institutional Regime, Opportunity Space and Organizational Path Constitution: Case Studies of the Conversion of Military Firms in China. J. Manag. Stud. 2015, 53, 552-579. [CrossRef]

6. Song, C.H.; Elvers, D.; Leker, J. Anticipation of converging technology areas-A refined approach for the identification of attractive fields of innovation. Technol. Forecast. Soc. Chang. 2016, 116, 98-115. [CrossRef]

7. Tu, Z.; Gu, X. Study on process of industry-university-research institute collaborative innovation based on knowledge flow. Stud. Sci. 2013, 31, 1381-1390.

8. You, G.; Yan, H.; Zhao, X. The Policy System Construction on the Development of Civil-military Integration: Quo Status, Problems and Countermeasures. Forum Sci. Technol. China 2017, 1, 150-156.

9. Acosta, M.; Coronado, D.; Ferrandiz, E.; Marin, M.R.; Moreno, P.J. Patents and dual-use technology: An empirical study of the world's largest defence companies. Def. Peace Econ. 2018, 29, 821-839. [CrossRef]

10. Tran, T.A.; Kocaoglu, D.F. Literature review on technology transfer from government laboratories to industry. In Proceedings of the PICMET ‘09-2009 Portland International Conference on Management of Engineering \& Technology, Portland, OR, USA, 2-6 August 2009; pp. 2771-2782.

11. Mowery, D.C. Handbook of The Economics of Innovation; Military R\&D and Innovation: Amsterdam, The Netherlands, 2010; Volume 2, pp. 1219-1256. [CrossRef]

12. Fitzgerald, B.; Parziale, J. As technology goes democratic, nations lose military control. Bull. At. Sci. 2017, 73, 1-6. [CrossRef]

13. Zullo, R.; Liu, Y. Contending with Defense Industry Reallocations: A Literature Review of Relevant Factors. Econ. Dev. Q. 2017, 31, 360-372. [CrossRef]

14. Avadikyan, A.; Cohendet, P.; Dupouët, O.; Avadikyan, A.; Cohendet, P.; Dupouët, O. A Study of Military Innovation Diffusion Based on Two Case Studies. In Innovation Policy in a Knowledge-Based Economy; Springer Science and Business Media LLC: Berlin/Heidelberg, Germany, 2005; pp. 161-189.

15. Curran, C.-S. The Anticipation of Converging Industries. Anticipat. Converg. Ind. 2013, 45, 34-43.

16. Gansler, J.S. Integrating civilian and military industry. Issues Sci. Technol. 1988, 5, 68-73. 
17. Diebold, W.; Alic, J.A. Beyond Spinoff: Military and Commercial Technologies in a Changing World. Foreign Aff. 1992, 71, 204. [CrossRef]

18. Matelly, S.; Lima, M. The influence of the state on the strategic choices of defence companies: The cases of Germany, France and the UK after the Cold War. J. Innov. Econ. 2016, 20, 61. [CrossRef]

19. Seró, M.A.; Coronado, D.; Marín, R. Potential Dual-Use of Military Technology: Does Citing Patents Shed LihgtI on This Process? Def. Peace Econ. 2011, 22, 335-349. [CrossRef]

20. Brandt, L. Defense conversion and dual-use technology: The push toward civil-military integration. Policy Stud. J. 2010, 22, 359-370. [CrossRef]

21. Uttley, M.R.H. Democracy's arsenal: Creating a twenty-first-century defense industry. Def. Secur. Anal. 2011, 28, 194-195. [CrossRef]

22. Sillers, T.S.; Kleiner, B.H. Defence conversion: Surviving (and prospering) in the 1990's. Work Study 1997, 46, 45-48. [CrossRef]

23. Pamen, O.M. Optimal Control for Stochastic Delay Systems Under Model Uncertainty: A Stochastic Differential Game Approach. J. Optim. Theory Appl. 2015, 167, 998-1031. [CrossRef]

24. Yin, S.; Li, B. Transferring green building technologies from academic research institutes to building enterprises in the development of urban green building: A stochastic differential game approach. Sustain. Cities Soc. 2018, 39, 631-638. [CrossRef]

25. Wang, J.-Y.; Blomström, M. Foreign investment and technology transfer. Eur. Econ. Rev. 1992, 36, 137-155. [CrossRef]

26. Koessler, F. Strategic knowledge sharing in Bayesian games. Games Econ. Behav. 2004, 48, 292-320. [CrossRef]

27. Podvezko, V. Others Game theory in building technology and management. J. Bus. Econ. Manag. 2008, 3, 237-239. [CrossRef]

28. Wei, M.; Chen, G.; Cruz, J.B.; Hayes, L.; Krüger, M.; Blasch, E. Game-theoretic modeling and control of military operations with partially emotional civilian players. Decis. Support Syst. 2008, 44, 565-579. [CrossRef]

29. Li, J.; Yi, J.; Zhao, Y. Effective Boundary of Innovation Subsidy: Searching by Stochastic Evolutionary Game Model. Symmetry 2020, 12, 1531. [CrossRef]

30. Stowsky, J. Secrets to shield or share? New dilemmas for military R\&D policy in the digital age. Res. Policy 2004, 33, 257-269. [CrossRef]

31. Sydow, J.O.R.; Schrey, G.; Koch, J. Organizational path dependence: Opening the black box. Acad. Manag. Rev. 2009, 34, 689-709.

32. Anzola-Rom, A.N.P.; Bayona, C.; Garc-Marco, T. Organizational innovation, internal R\&D and externally sourced innovation practices: Effects on technological innovation outcomes. J. Bus. Res. 2018, 91, $233-247$.

33. Liu, G.; Zhang, J.; Tang, W. Strategic transfer pricing in a marketing-operations interface with quality level and advertising dependent goodwill. Omega 2015, 56, 1-15. [CrossRef]

34. Zhao, L.M.; Sun, J.H.; Zhang, H.B. Technology sharing behavior in civil-military integration collaborative innovation system based on differential game. J. Ind. Eng. Eng. Manag. 2017, 31, 183-191.

35. Basar, T.; Olsder, G.J. Dynamic Noncooperative Games; Academic Press: New York, NY, USA, 1995.

36. Hausken, K. Governments Playing Games and Combating the Dynamics of a Terrorist Organization. Int. Game Theory Rev. 2020, 36. [CrossRef]

37. Dockner, E.J.; Jorgensen, S.; van Long, N.; Sorger, G. Differential Games in Economics and Management Science; Cambridge University Press (CUP): Cambridge, UK, 2000.

38. Hausken, K. Production and Conflict Models Versus Rent-Seeking Models. Public Choice 2005, 123, 59-93. [CrossRef]

Publisher's Note: MDPI stays neutral with regard to jurisdictional claims in published maps and institutional affiliations.

(C) 2020 by the authors. Licensee MDPI, Basel, Switzerland. This article is an open access article distributed under the terms and conditions of the Creative Commons Attribution (CC BY) license (http://creativecommons.org/licenses/by/4.0/). 